\title{
Mitigating Examination Malpractices in Nigerian Universities using an Enhanced Automated Essay Scoring System
}

\author{
Tina Ngozi Olisa \\ Department of Computer Science \\ Ignatius Ajuru University of Education, Nigeria
}

\author{
Friday Eleonu Onuodu \\ Department of Computer Science \\ University of Port Harcourt, Nigeria
}

\begin{abstract}
Education, being a process of teaching and learning is evaluated through examination at the end of the learning period. Examinations not only serves as a feedback for the trainer to ascertain the level of knowledge acquired but also serves as a measure of knowledge retention by the trainee. Any misconduct or irregularity distorts this feedback mechanism and gives a false outcome of the learning process and has negative consequences. In Nigeria, examination malpractice has reached an alarming stage and in recent times this concern has been echoed across the country. Many suggestions on containing the crisis focus on correcting the attitude of students, teachers and the government but the situation seems to have worsened as implementation of these recommendations remain a challenge. In this research, an alternative approach which is the use of Automated Essay Scoring technique for assessing student's examinations is proposed. This approach would significantly discourage examination malpractice and provide better control, accuracy and efficiency in examinations.
\end{abstract}

\section{General Terms}

Examination, Automated Essay Scoring techniques

\section{Keywords}

Education, Examination Malpractice, Educational Institution, Automated Essay Scoring.

\section{INTRODUCTION}

Education as defined by the Longman Dictionary of Contemporary English (5th Edition) is a method of teaching and learning. According to Akaranga and Ongong (2013), education is an essential process through which individuals are prepared to lead live productively according to their diverse abilities and interests.

Formal education or the western form of knowledge acquisition is measured with the award of certificates. Before certificates are awarded, students must have been assessed or examined in the respective fields they have been trained on. According to Nnam and Inah (2015), examination is a benchmark against which a student or candidates competency is formally assessed in the formal educational sector. George and Ukpong (2013) also opined that the commonest means by which the entirety of educational system revolves is the examination.

Examinations that involve essays are widely considered as an essential and indispensable key in the learning process as it plays a major role in assisting instructors to identify the achievements of students and their circumstances during the learning process. It is considered to be a measurement of the learner's capacity to remember, put in order, examine and write thoughts that are focused on particular topics. Generally, essay examinations suits a smaller group of candidates and this gradually decreases when the number significantly gets larger. Additionally, this method of examination eliminates guess work from the learner, since it depends on free answer rather than opting for the right answer as is done in multiple choice tests.

Examination malpractice is described by the Examination Malpractice Act as any act of omission or commission by a person who in expectation of, before, during or after any examination deceitfully obtains an unfair advantage for himself or any other person in such a way that violates the laid down rules and regulations to the point of undermining the validity, reliability, authenticity of the examination and eventually the integrity of the certificates issued.

\section{RELATED WORK}

Atabong et al. (2010) in their work on eliminating examination malpractices in Africa using Automated test taking, marking and result printing. They opined that upon the conclusion of every examination, the system automatically issues the results of the test taker as a report showing all the courses taken, grades, performance and rank. Their results showed that there was no human interference such as examiner, the candidate and the course administrator during and after the examination. Although, their system could provide the necessary convenience for both administrator and local user, they could not acquire the necessary computers and peripheral devices for the effective application of the system to institutions since the number of computers must be relative to the number of test takers.

Onyibe et al. (2015) presented a work on Computer based testing (CBT) technique in Nigeria. In their work, they opined that computer based testing made possible an opportunity to measure intricate forms of knowledge and perceptive that was not possible through the traditional paper based testing method. They noted that CBT could assess both cognitive and practical abilities of test takers. Their work also showed diverse benefits of CBT which included; digital recording of student's data, enhanced reliability in test marking, unbiased assessment, improved test security, instant feedback to test takers, lower long term costs etc. However, the system of CBT was not so effective as computer education is not required in every level of education and teachers' education programme curriculum did not have practical contents in ICT. Also, there was the challenge of lack of funding from all tiers of government in the education sector for the acquisition of the necessary ICT infrastructure and equip CBT centres to improve e-learning capacity in terms of human and material resources. 
Olawale et al (2014) presented a work on E-Exams systems for Nigerian Universities with emphasis on security and result integrity. They proposed an electronic examination system that used both biometric fingerprint authentication and cryptography to guard test questions in academic institutions in order to realise desired security levels at the different phases of the examination process. Their work showed the use of a biometric fingerprint system and decryption and encryption of texts. They employed a method were each principal actor in the examination system - students, lecturers and administrators had their biometric finger print registered as categorized and test questions encrypted and decrypted as required. The system when implemented fully will drastically reduce the unnecessary interference of humans, impersonations, taking of bribe by lecturers, invigilators and supervisors, excessive paper work, examination leakages and reduction in number of human invigilators required to invigilate in examination halls. Their work however did not take into consideration the economic issues and psychological aspects related with the implementation of the proposed system.

Ade-Ibijola et al (2012) presented a work on an Expert System for Automated Essay Scoring (AES) in computing using shallow NLP Techniques for inference. They developed an Expert system for scoring free-text answers and adapted it to the academic assessment process in the Nigerian university system. They built a knowledge base and were able to populate it with answer templates or model answers from lecturers in a specific course, they designed an inference engine using information extraction, attached a fuzzy module for correctness evaluation and developed two-web applications user interfaces - for lecturers to set their test questions and supply answer templates and the other for students' to write open-ended tests online and obtain an instantaneous feedback of their performance. The main task of their system was to evaluate the correctness of students' answers. This system was able to store students' names and matriculation numbers, enable students modify test response when they haven't been submitted, compare the students' answer to the model answer(s) and generate score based on the correctness of the students' answer, present the score to the student as feedback etc. However, their system was not suitable to assess free-text answers where the word order is important; it was also more effective in applications to short text answers rather than bulky texts. In addition, another problem encountered in this research was the lack of a good standard to calibrate human marks and of a clear set of rules for specifying teachers' texts and also the lack of standard data collection.

Zhang Qiang (2014) presented an Experimental Research on applying Automated Essay Scoring System to college English writing course and he was able to propose approaches on the application of AES system in English writing course in colleges. He opined that computer grading should be in combination with teachers' instruction and evaluation, combining timed composition and composition after class, combination of the product writing approach and the process writing approach. However his work did not focus on detailed feedback from the students, universality of the scoring model and the clear division between human and computer interface.

Siddhartha et al (2010) designed an Automated Essay Grading (AEG) System in the Indian context. Their work showed that while most AES systems graded an English essay, it considered other local languages as inaccurate. They developed a framework under Indian context for an AEG which could be for rectifying essays written in Indian languages and likewise writing improved English essays. However, their work did not consider the solution for machine translated essays, capturing mental status of students writing essays and the detection of anomalous essays.

Valenti et al (2003) presented an overview of current approaches to the automated assessment of free text answers on automated essay grading. They noted that automated essay marking platforms mainly assess essays either for content or for style or for some systems taking into account both aspects. The challenges they noted where encountered in the research on AEG was that there was no effective standard to calibrate human marks and a clear set of rules for selecting master texts. However, the constraints noted were the lack of a standard data collection and unified measure to relate the performance of the systems not being defined.

Ana et al (2013) presented a work on the design and implementation of an online examination administration system for universities. They opined that the implementation of an efficient and operative online examination system that enables student results to be computed and released immediately and storage of these data in a central database would encourage future planning and cause a balance within the tertiary institution system. Their system was developed using Microsoft visual studio 2008 and the features of the application included the ability to randomise questions, regulate the examination time, manage questions storage in a database, validate student identification, monitoring of the system in real time and auto grading exams. Their system was able to solve the problem it was intended for as per its requirement specificationsr.

\section{MATERIALS AND METHODS}

\subsection{Analysis of the Existing System}

The automated test taking system presented by Ana and Bukie (2013) was a way forward for the eradication of the menace caused by the manual system of examination with the use of a computerized test taking, marking and printing of student results. The drawbacks of existing framework include;

i. The existing system is a means of formative assessment, i.e it is an assessment that is more diagnostic than evaluative.

ii. This system encourages guess work from the student, hence its grading does not really evaluate a students know how.

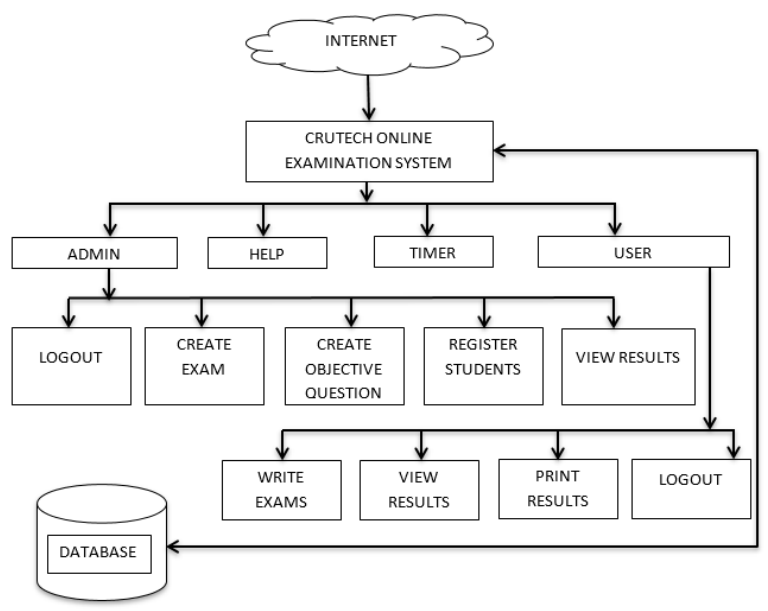

Figure 1: Architecture of Existing System (Ana et al, 2013) 


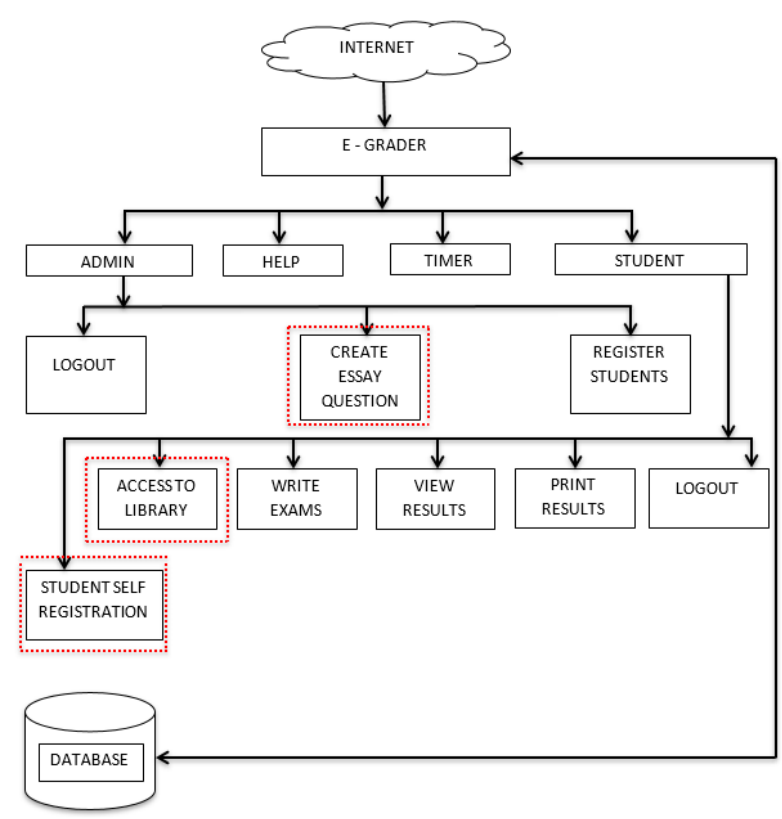

Figure 2: Architecture of the Proposed System

The design of this system was done to increase the efficiency, reliability and accuracy of the existing system, making it more flexible and comprehensible by the user. The modules of the proposed system include:

\section{i. Login/Logout}

Login and logout enables both the user (student)/Admin to gain access in and out of the proposed system.

\section{ii. Create Essay Questions}

As the name implies, it enables the administrator to create essay questions. The administrator after creating the questions, lists the parameters/keywords required for the pattern-match grading, the number of words required for the essay and also the required time for the essay.

\section{iii. Register Student}

For examination eligibility, the student must be registered and their details stored in the database. The student is assigned a username and password to enable access to the examination portal. This registration of student can be done by both the student and the Admin.

\section{iv. Timer}

The role of the timer in this system is to time and encourage the student during the examination to be time conscious. The user is able to view the time allocation for the question and once the exam begins it begins to count down.

\section{v. Access to Library}

This enables students to have access to educational materials when required.

\section{vi. Write Exams}

To access the examination, the student must login with his username and password created by the administrator. After successfully logging in, the student proceeds to answer the short text essay and at the end of it proceeds to click on the submit button. After clicking submit, the student is assessed and presented with the result immediately.

\section{vii. Print Results}

After a student submits a completed essay and is scored, the student is able to print the result of the graded essay.

\section{viii. Student Self-Registration}

The system enables a new student to carry out self-registration and the information provided by the student is stored in the database.

\subsection{Advantages of the Proposed System}

i. There is consistency in data Management, as only authorized persons are allowed access to the database.

ii. The system is intelligent and has a secure and robust database of students.

iii. There is less human intervention in the examination and results processing hence there is no room for biased grading.

iv. It reduces the menace of examination malpractice as grading is immediate

v. This system is an effective means of formative assessment; as it has the ability to grade essay questions.

vi. There is accuracy in this system as grading is done on pattern-match question type.

\section{RESULTS AND DISCUSSION}

\subsection{Home page}

This is the Home page of the system which gives the user the option of selecting either student login or admin login as shown in figure 3.1

\subsubsection{Student Login Page}

The Figure 3.2 allows the student to enter login credentials to enable him/her begin the essay writing. It also enables a student who is not registered in the student database to proceed with student self-registration. In Figure 3.3, student enters his/her details to create a unique user name and password.

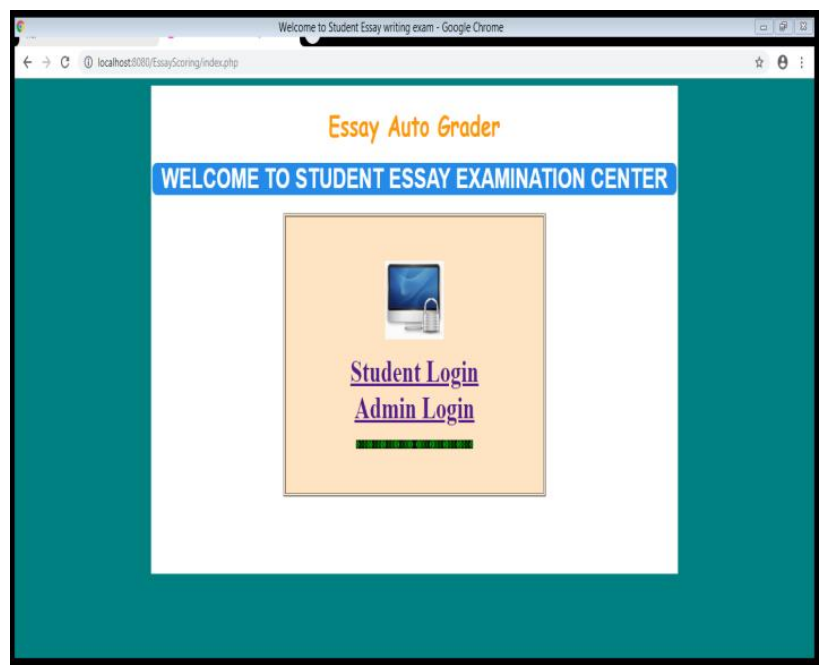

Figure 3.1: Home page of the Essay Grader System 


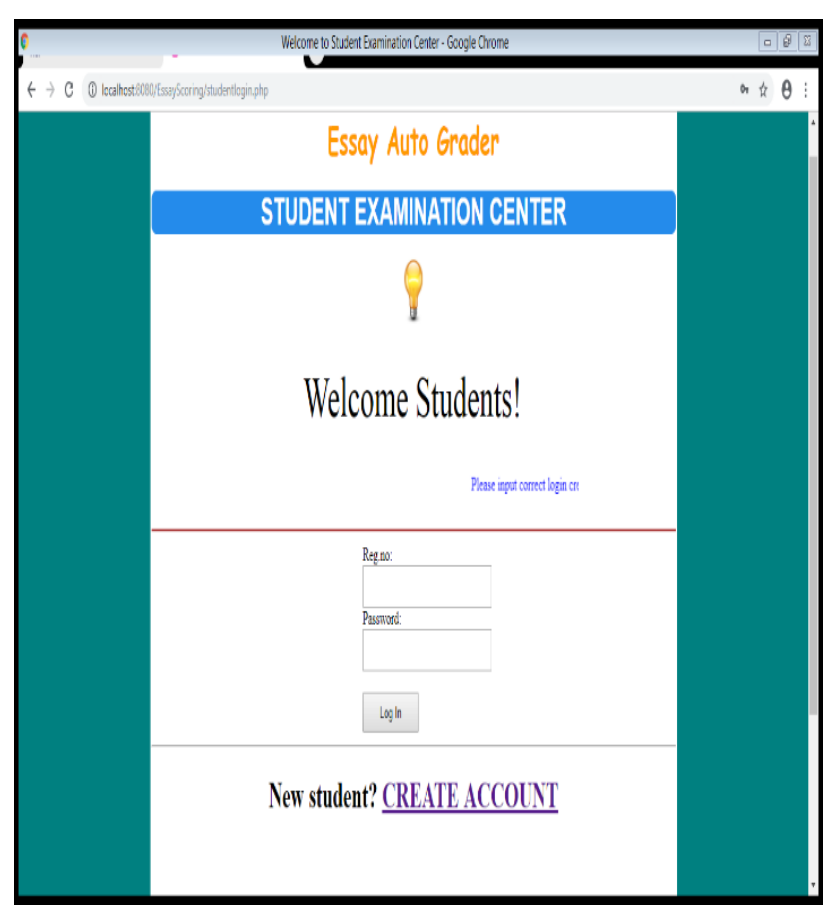

Figure 3.2: Student Login Page of the Essay Grader System

Figure 3.4 is the Administrator login page. When the right credentials are entered, admin is able to insert/delete/modify student record, set essay question, time the given essay and set the key phrases for the essay.

Figure 4.6 is the essay writing page. It shows the essay question, and a timer that counts down. At the end of the essay, the student can submit or if time runs out, the essay

automatically gets submitted. In figure 4.7 , the essay is graded based on given criteria and the student can proceed to print his/her script.

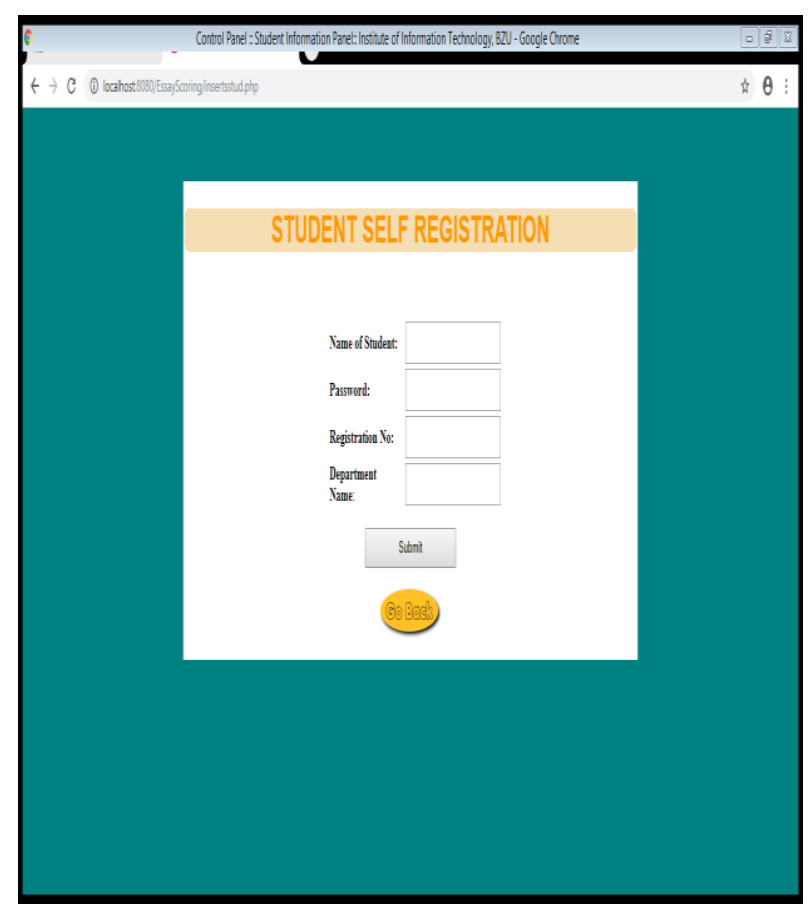

Fig 3.3: Student Self Registration Page of the Essay Grader System

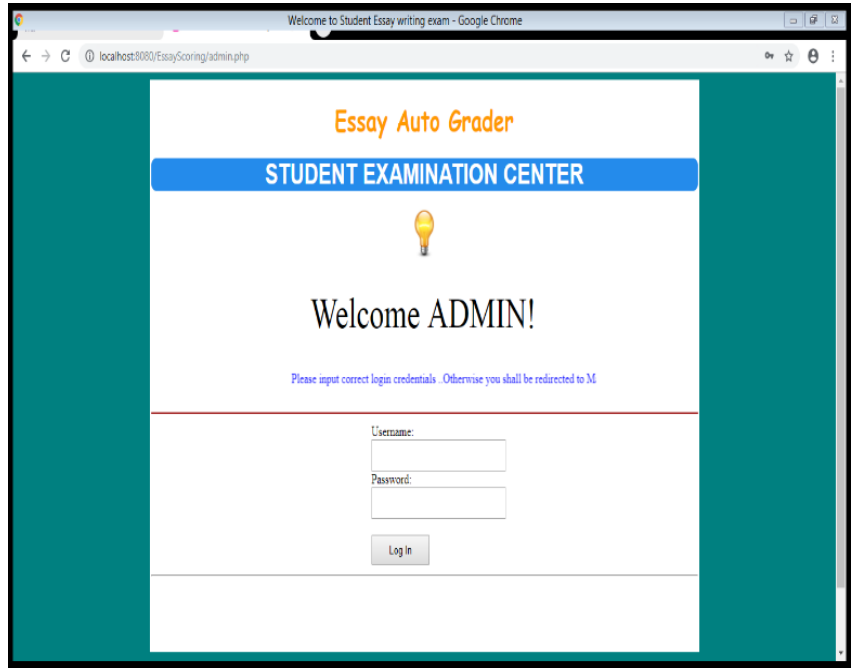

Figure 3.4: Administrator Login Page of the Essay Grader System

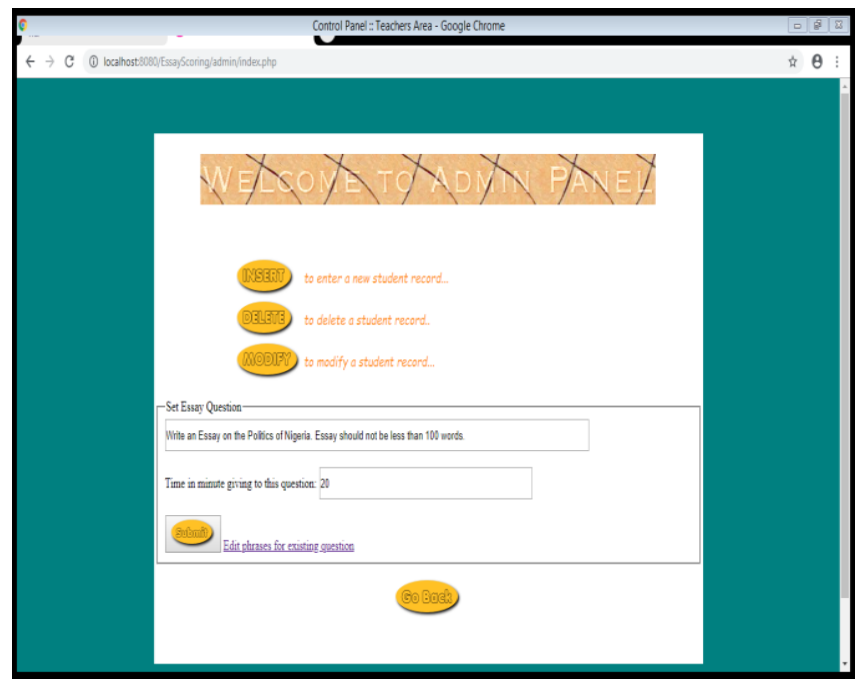

Figure 3.5: Administrator Page of the Essay Grader System

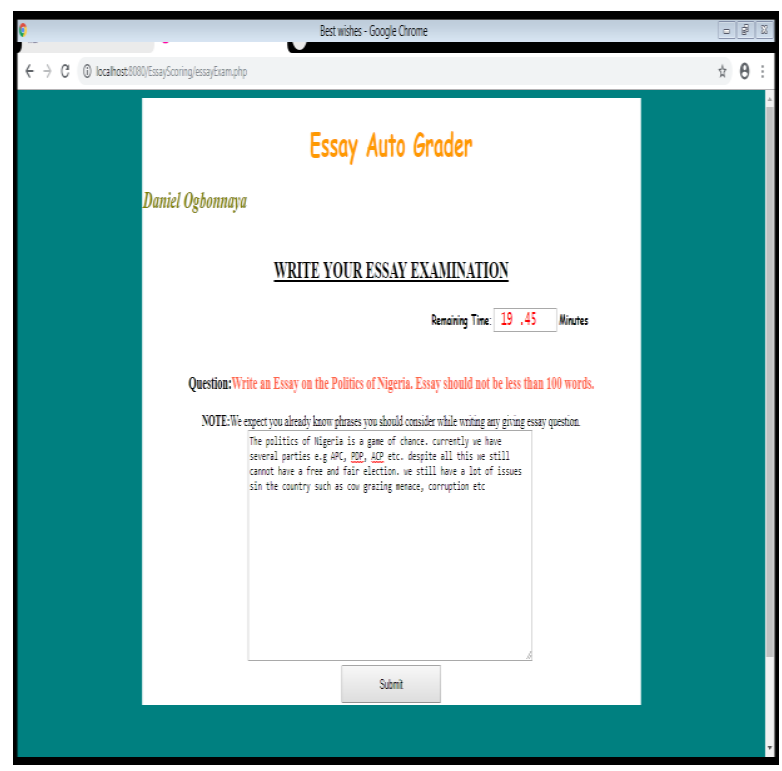

Figure 3.6: Essay writing Page of the Essay Grader System 


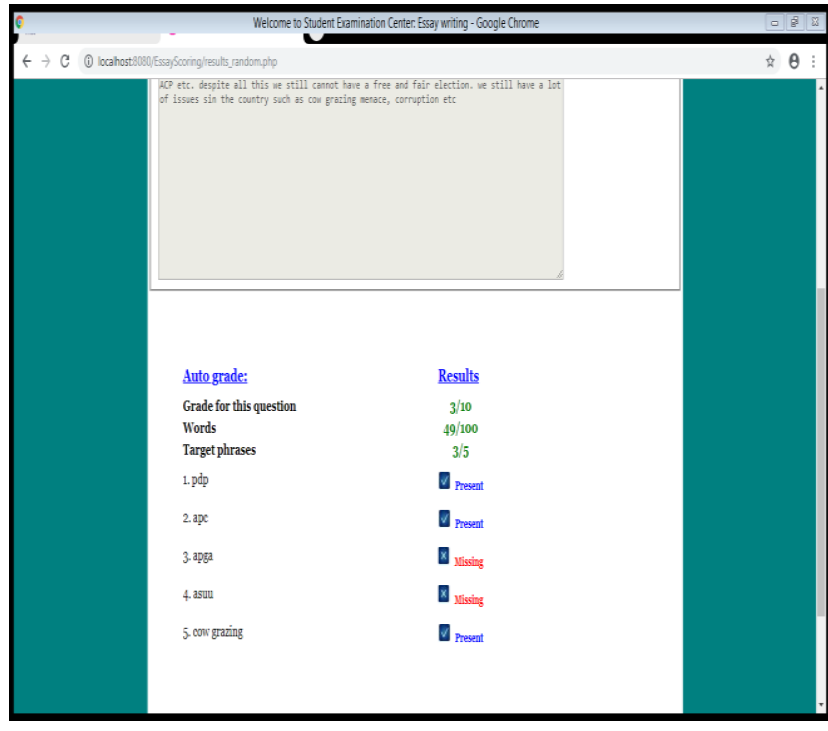

Figure 3.7: Preliminary Result Page of the Essay Grader System

\section{CONCLUSION}

The application of the scoring system provides the required convenience for the teacher and the student. This system has without doubt achieved its aims and objectives which included having an unbiased assessment of students' examination, having an option for assessment using computers to present information and having a consistent and secured means of test taking and marking. This study has been able to automate the practice in the conventional essay assessment system by making use of a grading system that is free of unnecessary human intervention on exam questions and answers. The use of this scoring process does not mean that teachers cease to score and review students essays any longer, rather their responsibility becomes more varied; they could be helpers, supervisors and responders in the student's examination activities.

\section{RECOMMENDATIONS}

The use of automated scoring applications will be beneficial to Nigerian university institutions due to the irregularities of the human grading system (manual system) of test taking and scoring. It is recommended that both teachers and students be enlightened on the basic use of computers so as to enable a flawless switch to the automated system of examinations. Also there is need for government funding to acquire the necessary computers and peripheral devices for effective implementation of this system in educational institutions.

\section{CONTRIBUTION TO KNOWLEDGE}

The Auto essay grader has achieved its aim and objectives by overcoming the shortcomings of the manual and summative means of assessment. The system provides the following added value to the assessment system of institutions

i. The implementation of the system provides an enhanced effective means of formative assessment that mitigates examination malpractice in essay writing examinations. With the addition of the 'create essay question' feature, the administrator is able to curb the menace of student's malpractices. to register themselves and have their data stored in the required database

ii. The system enables students to carry out selfregistrations and have access to library of educational materials, thereby giving both the administrator and user the required convenience before, during and after the examination.

\section{REFERENCES}

[1] Ade-Ibijola, A.O., Wakama, I. and Amadi, J.C. (2012). An expert system for automated essay Scoring (AES) in computing using shallow NLP techniques for inferencing. International Journal of Computer Applications, 51(10), 37 - 45.

[2] Ahmed, A., Abdulkareem A., Fawaz K. A., Khalid A., Malek A. (2015), AutoScor: An Automated System for Essay Questions Scoring. International Journal of Humanities, Social Sciences and Education, 2(5), 182 187

[3] Akaranga, S. I., and Ongong, J. J. (2013). The phenomenon of Examination Malpractice: An Example of Nairobi and Kenyatta Universities. Journal of Education and Practice, 4(18): $87-96$

[4] Ana, P. and Bukie P. T. (2013). Design and Implementation of Online Examination Administration System for Universities. Global Journal of Mathematical Sciences, 12, 39 - 51

[5] Anzene, S. J. (2014). Trends in Examination Malpractice in Nigerian Educational System and its Effects on the Socio-Economic Development of Nigeria. Asian Journal of Humanities and Social Sciences, 2(3): 1 8

[6] Atabong, T.A., Okpala, M.C., Abondem, A. L. and Essombe,C.E. (2010), Eliminating Examination

Malpractice in Africa with Automated Test Taking, Marking and Result Printing. Tropical Journal of Biomedical and Allied Sciences Research, 4(1), 452 468

[7] Attali, Y. \& Burstein, J. (2006). Automated Essay Scoring with e-rater V.2 Journal of Technology, Learning, and Assessment (JTLA), 4(3).

[8] Attali, Y. (2004). Exploring the feedback and revision features of Criterion. Paper presented at the National Council on Measurement in Education (NCME), San Diego, CA.

[9] Bereiter, C. (2003). Foreword. In Mark D. Shermis and Jill C. Burstein (Eds.), Automated essay scoring: a cross disciplinary approach (pp. vii-ix). Mahwah, NJ: Lawrence Erlbaum Associates.

[10] Baron, D. (2005). The college Board's new essay reverses decades of progress toward literacy. The chronicle of Higher Education, P.B14.

[11] Bloom, B.S. (1956). Taxonomy of educational objectives: The classification of educational goals. Handbook I, Cognitive domain. New York, Toronto: Longmans, Green.

[12] Burstein, J., Kukich, K., Wolff, S., Lu, C., and Chodorow, M. (1998). Computer analysis of essays. Proceedings of the NCME Symposium on Automated Scoring, Montreal, Canada.

[13] Burstein, J., Kukich, K., Wolff, S., Lu, C., Chodorow, M., Braden-Harder, L., M.D. (1998). Automated scoring using a hybrid feature identification technique. In Proceedings ofthe $17^{\text {th }}$ international conference on computational linguistics - Volume 1 (pp. 206 
210). Association for Computational Linguistics.

[14] Burstein, J. (2003). The e-rater scoring engine: Automated Essay Scoring with

[15] natural language processing. In M. D. Shermis and J. C. Burstein (Eds.), Automated Essay Scoring: A cross disciplinary approach (pp. 113-121). Mahwah, NJ: Lawrence Erlbaum Associates.

[16] Burstein, J. and Chodorow, M. (1999). Automated Essay Scoring for nonnative English speakers. Proceedings of the ACL99 Workshop on Computer-Mediated Language Assessment and Evaluation of Natural Language Processing, College Park, MD.

[17] Chen H., He B., Luo T., and Li B. (2012), A Rank-based learning approach to Automated essay scoring. 2012 Second International Conference on Cloud and Green Computing, DOI 10.1109/CGC.2012.41

[18] Chung, G. K.. and O’Neial, H. F (1997). Methodological approaches to online scoring of essays. Citeseer.

[19] Cohen, Y., Ben-Simon, A., and Hovav, M. (2003). The Effectof Specific Language Features on the Complexity of Systems for Automated Essay Scoring. Paper presented at the $29^{\text {th }}$ Annual Conference of the International Association for Educational Assessment,Manchester,UK. http://www.aqa.org.uk/support/iaea/papers/bencohenhovav.pdf

[20] Daradoumis, T., Bassi, R., Xhafa, F., Caballe, S., (2013). A Review on Massive E-Learning (MOOC) Design, Delivery and Assessment. 2013 Eight International Conference on P2P, Parallel, Grid, Cloud and Internet Computing, DOI10.1109/3PGCIC.2013.37,208 - 213

[21] Dikli, S. (2006). An overview of automated scoring of essays. Journal of Technology, Learning and Assessment, 5(1).

[22] Dreher H., Williams R., and Palmer J., (2002). Automated essay grading system applied to a first year university subject-How can we do it better. Proceedings of the Informing Science and IT Education (InSite) Conference, Cork, Ireland, 1221 - 1229

[23] Elliot, S.M. (2003). IntelliMetric: From Here to Validity. In M. D. Shermis

[24] and J. Burstein (Eds.), Automatic Essay Scoring: A Cross-Disciplinary Approach 71-86: Lawrence Erlbaum Associates.

[25] Emaikwu, S. O. (2012). Assessing the Impact of Examination Malpractices on the Measurment of Ability in Nigeria. International Journal of Social Sciences \&Education, 2(4): 748 - 757

[26] Fagbola T. M., Adigun A. A. and Oke A. O., (2013), Computer-Based Test (CBT) System for University Academic Enterprise Examination. International Journal of Scientific \& Technology Research, 2(8), 336 - 342

[27] George, I. N. and Ukpong, D. E. (2013). Contemporary Social Problems in Nigeria and its Impact on National Development: Implication for Guidance and Counselling Services. Journal of Educational and Social Research, 3(2): $167-173$

[28] Hearst, M. (2000). The debate on automated essay grading. IEEE Intelligent Systems, 15(5), 22 - 37, IEEE CS Press.

[29] Herrington, A., Moran, C. (2001). What happens when machines read our students' writing? College English, $634,480-499$

[30] Jimoh, B. O. (2009). Examination Malpractice in Secondary Schools in Nigeria: What sustains it? European Journal of Educational Studies, 1(3): 101 108

[31] Kaplan, R. M., Wolff, S., Burstein J. Li, C., Rock D., and Kaplan, B., (1988). Scoring essays automatically using surface features, Technical Report 94-21P, New Jersey, USA: $\quad$ Educational Testing Service

[32] Kukich, K. (2000). Beyond Automated Essay Scoring. In M. A. Hears (Ed.), The debate on automated essay grading. IEEE Intelligent systems, 27-31.

[33] Landauer, T.K., Laham, D. and Foltz, P.W. (2003). Automated scoring and annotation of essays with the Intelligent Essay Assessor. In M.D. Shermis \& J. Burstein (Eds.), Automated Essay Sscoring: A CrossDisciplinary Perspective, 87-112. Mahwah, NJ Lawrence Erlbaum Associates.

[34] Landauer, T. K., Laham, D., and Foltz, P. W. (2003). Automated Essay Scoring: A cross disciplinary perspective. In M. D. Shermis and J. C. Burstein (Eds.), Automated Essay Scoring and annotation of essays with the Intelligent Essay Assessor. 87-112 Mahwah, NJ Lawrence Erlbaum Associates.

[35] Landauer, T. K., Laham, D., Rehder, B. and Schreiner, M. E. (1997). How well can passage meaning be derived without using word order? A comparison of Latent Semantic Analysis and humans. Proceedings of the 19th Annual Conference of the Cognitive Science Society, 412-417

[36] Larsen-Freeman, D and Cameron, L. (2008). Complex systems and applied linguistics. Oxford: Oxford University Press.

[37] Lemaire, B. and Dessus, P. (2001). A system to assess the semantic content of student essays. Educational computing research, 24(3), 305-306

[38] Nnam, M.U., and Inah, A. F. (2015). Empirical Investigation into the Causes, Forms and Consequences of Examination Malpractice in Nigerian Institutions of Higher Learning. International Journal of Novel Research in Humanity and Social Sciences,2(1): $52-62$

[39] Murray, B. (1998). The latest techno tool:Essay grading computers. American Psychological Association (APA), 8(29).

[40] Nichols, P. D. (2004). Evidence for the interpretation and use of scores from an Automated Essay Scorer. Paper presented at the Annual Meeting of the American Educational Research Association (AERA),San Diego, CA.

[41] Odunayo, E.O., Ibrahim, A.A., Stephen O.O. and Elijah O.O (2015), Evaluation of N-gram Text Representations for Automated Essay-Type Grading Systems. International Journal of Applied Information Systems, $9(2)$

[42] Ojonemi, P.S., Enejoh, W., Enejoh, A., and 
Olatunmibi, O. (2013). Examination Malpractice: Challenges to Human Resource Development in Nigeria. International Journal of Capacity Building in Education and Management, 2(1): 91 - 101

[43] Olawale A., Shafi'I M. A., E-Exams System for Nigerian Universities with Emphasis on Security and Result Integrity. International Journal of the Computer, the Internet and Management (IJCIM), 18(2)

[44] Onuka, A., and Amoo, S. A. (n.d). Examination Malpractice and Act 33 of 1999. Retrieved November 25, 2018 from www.naere.org.ng/journal/examination_malpractice_act _33_1999.pdf

[45] Onyibe C.O., Nwachi-Ikpor Juliana O., Abdulhakim A.A. (2015), Computer Based Testing Techniques in Nigeria: Prospects and Challenges. Journal of Information Engineering and Applications, 5(10).

[46] Page, E. B. (2003). Project Essay Grade: PEG. In M. D. Shermis and

[47] J. Burstein (Eds.), Automated essay scoring: A crossdisciplinary perspective, 43-54. Mahwah, NJ: Lawrence Erlbaum Associates.

[48] Page, E. B. (1994). Computer Grading of Student Prose, Using Modern Concepts and Software, Journal of Experimental Education, 62,127-142.

[49] Page, E. B. \& Petersen, N. S. (1995). The computer moves into essay grading: Updating the ancient test. Phi Delta Kappan, 76, 561-565.

[50] Page, E.B. (1966). The imminence of grading essays by computer. Phi Delta Kappan, 48, 238-243.

[51] Ramalingam V.V., Pandian A., Chetry P., and Nigam H. (2018). Automated Essay Grading using Machine Learning Algorithm. National conference on Mathematical Techniques and its Applications, doi 10.1088/1742-6596/1000/1/012030

[52] Rudner, L. M., and Gagne, P. (2001). An overview of three approaches to scoring written essays by computer.

[53] Rudner, L. M. and Liang, T. (2002). Automated essay scoring using Bayes' theorem. The Journal Technology, Learning and Assessment, 1(2).

[54] Shermis, M. D. and Burstein, J. (2003). Automated Essay Scoring: A cross disciplinary perspective. Mahwah, NJ: Lawrence Erlbaum Associates.
[55] Sadler, D. R. (1989). Formative Assessment and the Design of Instructional Systems. Instructional Science, $18,119-144$.

[56] Shermis, M.D., and Burnstein, J.C. (2002). Automated essay scoring, a crossdisciplinary perspective. NewJersey: Lawrence Erlbaum Associates.

[57] Shermis, M. and Berrera, F. (2002). Exit assessments. Evaluating writing ability through Automated Essay Scoring (ERIC document reproduction service no ED 464- 950.

[58] Sireci, S.G., and Rizavi, S. (2000). Comparing Computerized and Human Scoring of Students' Essays.

[59] Taghipour K. and Ng H. T. (2016), A neural Approach to Automated Essay Scoring. Proceedings of the 2016 Conference on Empirical Methods in Natural Language Processing, $1882-1891$

[60] Siddhatha G., Sameen S. F., (2010). Design of an Automated Essay Grading (AEG) System in Indian context. International Journal of Computer Applications, 1(11), 60 - 65

[61] Uzoigwe, G. O. (n.d). Corruption in Education and Assessment Systems: The WAEC Experience in Nigeria. Retrieved November $\quad 25, \quad 2018$ fromwww.iaea.info/documents/paper 1162d1b538.pdf

[62] Valenti S., Neri F., Cucchiarelli A. (2003), An Overview of Current Research on AutomatedEssay Grading. Journal of Information Technology Education, 2(1), 319 $-330$

[63] Vantage Learning, (n.d). Retrieved November 25, 2018 from, http://www.vantagelearning.com

[64] Williamson, D. M., Xi, X.and Breyer, F. J (2012). A Framework for evaluation and use of automated scoring. Educational Measurement:Issues and Practice, $31(1), 2-13$

[65] West-Smith P., Butler S., Mayfield E. (2018). Trustworthy Automated Essay Scoring without Explicit Construct

[66] Validity. The 2018 AAAI Spring Symposium Series, 95 102

[67] Zhang Q. (2014). An Experimental Research on Applying Automated Essay Scoring System to College English writing course. International Journal of English Language Teaching, 1(2), $35-41$. 